\title{
"MINHA MÃE ME ENTREGOU NAS MÃOS DO PROFESSOR PARA FAZER DE MIM O QUE QUISESSE E PUDESSE": MEMÓRIAS DA EDUCAÇÃO ESCOLAR EM ANGOLA
}

\author{
Washington Santos Nascimento*
}

\section{RESUMO}

Este artigo tem por objetivo entender os impactos da educação formal no processo de colonização impetrado por Portugal em Angola no século XX. Para tanto, pretende-se discutir a história das missões cristãs, responsáveis pela educação formal, bem como analisar as memórias de alguns angolanos que frequentaram as escolas missionárias como os militantes políticos e escritores Adriano Sebastião, Amélia de Fátima Cardoso, Raul David, Manuel Pacavira e Uanhenga Xitu.

Palavras- chave: Educação; Missões Religiosas; Memórias; Angola.

\begin{abstract}
This article aims to understand the impact of formal education in the colonization process brought by Portugal in Angola in the twentieth century. To this end, we intend to discuss the history of Christian missions, responsible for formal education, as well as analyzing the memories of some Angolans who attended missionary schools as political activists and writers Adriano Sebastian, Amelia Fatima Cardoso, Raul David, Manuel Pacavira and Uanhenga Xitu.
\end{abstract}

Keywords: Education, Religious Missions Memories Angola.

Ao se referir à educação tradicional africana, Amadou Hampate Ba (2010) diz que ela estava ligada à experiência e era integrada à vida. Ela começava no seio das famílias, onde pai, mãe ou os idosos eram mestres e educadores, ministrando as primeiras lições da vida, através da experiência, histórias, fábulas, lendas, máximas, adágios, etc., sendo desta forma ligada as às circunstâncias da vida. Este modelo sofrerá um forte impacto das missões cristãs que acentuam a sua presença em África, sobretudo, nas primeiras cinco décadas do século XIX.

O impacto destas missões na África não se circunscreveu apenas a construir igrejas, conversão das populações ou mesmo a tradução da Bíblia para as línguas africanas, elas criaram plantações experimentais de novos produtos agrícolas, ensinaram ofícios como gráficos, alfaiates, pedreiro e carpinteiro. Além de promoverem o comércio e a alfabetização e o ensino do tipo ocidental. Todas estas missões criaram escolas primárias, técnicas e secundárias ${ }^{1}$.

Em Angola elas tiveram uma ação mais duradoura sobre a população angolana, sobretudo as do mundo rural, do que a estrutura do Estado português. Provocaram alterações profundas na vida de todos os angolanos que mantiveram contato, ocasionando modificações na organização comunitária, nos processos de escolarização, na formação para o trabalho, nos comportamentos, nas expectativas pessoais, além de estabelecerem novas redes de contato inter-regionais e mesmo internacionais ${ }^{2}$. 
Contando com o apoio do Estado e da iniciativa privada em sua ação missionária, o catolicismo, segundo o Censo de 1960, era declarado por grande parte da população que estava sob o controle direto dos portugueses, ou seja, $51 \%$, enquanto os protestantes eram da ordem de $17 \%$ da população recenseada.

A explicação de como um regime assumidamente católico poderia permitir a presença de instituições protestantes em seu território remete à Conferência de Berlim $(1884-1885)^{3}$, da qual Portugal também foi um dos signatários ${ }^{4}$. O documento final determinava que os países que fariam parte da partilha do continente africano deveriam dar garantias de liberdade de culto a todas as missões cristãs independentemente das suas origens nacionais ou confessionais ${ }^{5}$. Dessa forma, os portugueses toleravam a presença de missões protestantes em seu território, apesar de considerá-las uma ameaça, sobretudo por ser uma "influência desnacionalizadora" sobre os nativos e mais especificamente sobre aqueles que estavam em processo de assimilação ${ }^{6}$. Sobre a história destas missões em Angola, tanto católicas, quanto protestantes, passaremos a discutir a seguir.

\section{Missões cristãs em Angola}

A história da presença católica em Angola se mistura com a própria chegada dos portugueses, pois, quando Diogo Cão desembarcou na foz do Zaire em 1482, ele levou a Lisboa quatro africanos, que foram convertidos à religião Católica. Estes, junto a seis missionários, regressaram para Angola em 1491, começando daí o processo de cristianização. Em 1596, o Papa cria a Diocese do Congo, responsável pelos reinos de Angola e Congo, instalando em 1861 um Seminário em Luanda. Entretanto, de maneira mais significativa, a chegada dos Missionários do Espírito Santo em 1866 trouxe para Angola uma série de missões e junto a elas igrejas, hospitais e escolas ${ }^{7}$.

Já as missões protestantes em Angola eram originárias dos Estados Unidos e do Canadá, de onde partiram em finais do século XIX ${ }^{8}$. Batistas, Congregacionistas, Metodistas ${ }^{9}$, Irmãos de Plymouth, Evangélicos e Adventistas instalaram missões nas regiões interioranas, onde não existia qualquer controle colonial, nem mesmo uma influência católica ${ }^{10}$. Entre 1880 e 1965, os batistas instalaram-se entre os bacongos, os metodistas na região entre Luanda e Malanje (de língua quimbundo) e as diversas igrejas congregacionistas dos Estados Unidos da América e do Canadá implantaram-se na região do centro de Angola, de língua umbundu, onde também se fixaram, na década de 1920, os Adventistas do Sétimo Dia ${ }^{11}$.

Ao longo dos primeiros trinta anos do século XX, o protestantismo no Planalto Central angolano reforçou seus laços com os umbundos e agiu como um fator de mudança social significativa, principalmente no aspecto linguístico, pois, ao incorporar o umbundu em suas pregações, os missionários acabaram por levar a língua (e a cultura umbundu) para outras áreas ${ }^{12}$. Assim, é possível entender como, por exemplo, "novos assimilados", como Xitu, se expressam também em quimbundo.

As missões protestantes e católicas construíram, ainda que de forma incipiente e fragmentária, uma "rede" de ensino regular em Angola, com o propósito inicial de converter os "infiéis" e "pagãos ${ }^{13}$ " e, também, de formar os "assimilados". Com base no mapa construído por Carlos Serrano (1988), é possível perceber a distribuição espacial das instituições de ensino católicas e protestantes: 
Mapa 5: Missões católicas e protestantes no território angolano

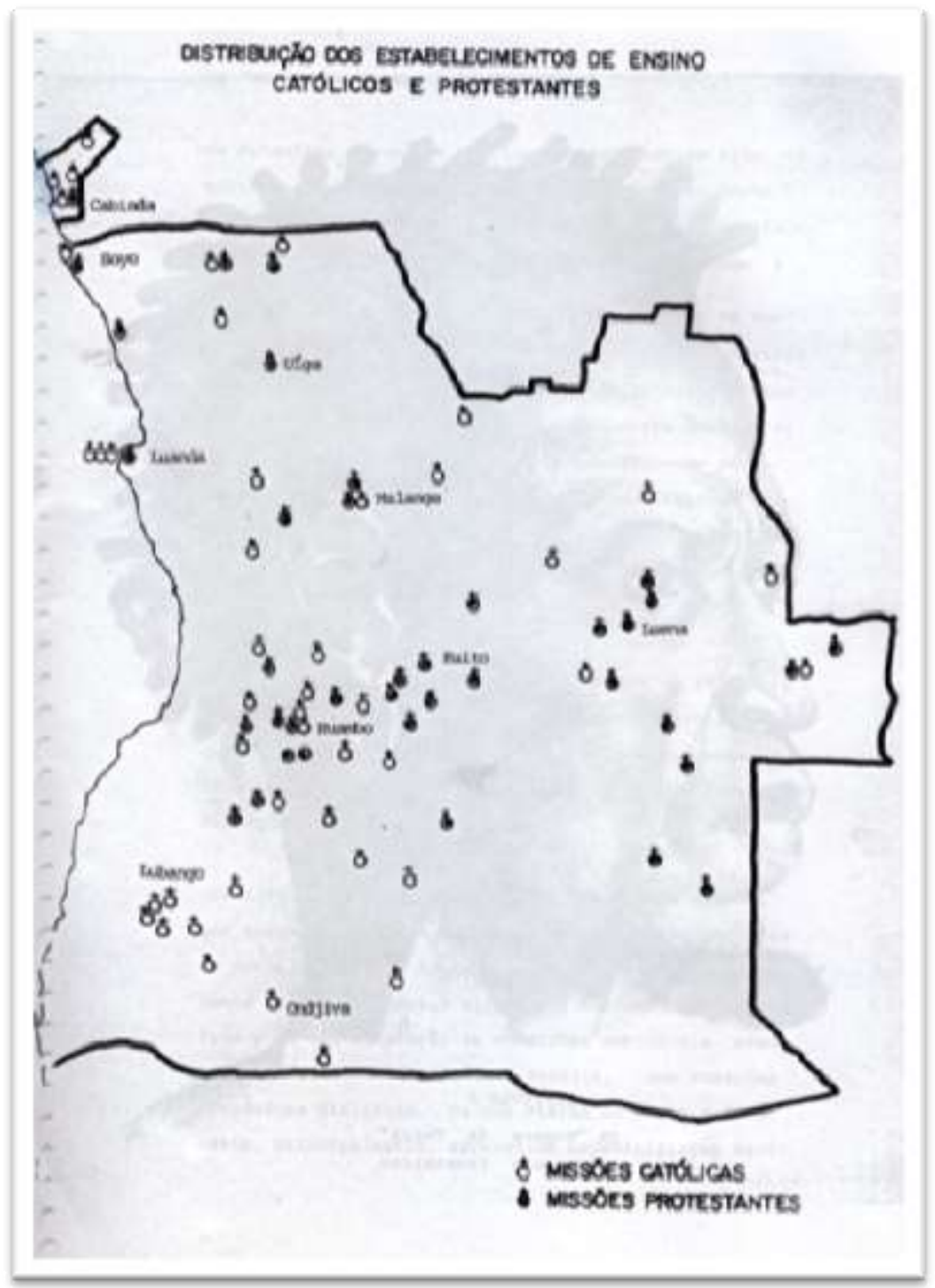

Fonte: SERRANO, Carlos. Angola, nascimento de uma nação: um estudo sobre a construção de identidade nacional. Luanda: Edições Kilombelembe, 2009. p. 107.

Apesar de suas diferenças, que vão desde a relação com o poder metropolitano até o ethos religioso, católicos e protestantes compartilhavam a mesma visão de que o africano deveria ser salvo pelos cristãos ${ }^{14}$. Mas ao mesmo tempo representavam, para as pessoas que estavam em sua zona de influência, certa segurança (religiosa e material), além de serem intermediários nas relações com o poder metropolitano.

As missões protestantes se tornaram mais procuradas pelos moradores do interior, por conta de melhor qualidade na oferta de escolas e de assistência médica, além da rejeição menor a determinados aspectos da organização social africana e uma representação mais positiva do "eu" angolano. Por essa razão, elas formaram mais assimilados do que as missões católicas. Para Messiant (1998), era um tipo novo de assimilado, com ainda mais questionamentos à metrópole ${ }^{15}$.

Missões protestantes e católicas, por meio da educação, ofereciam ao angolano a porta de entrada para uma das poucas mudanças "legais" possíveis, ou seja, tornar-se um 
assimilado, que passou a ser regulamentado pelo Estado salazarista a partir de um conjunto de leis, iniciado pelo Estatuto do Indigenato de 1926. Entretanto mais do que uma mudança no status legal, a vivência nas missões cristãs trouxe mudanças significativas na vida daqueles que futuramente se tornariam "novos assimilados".

Eles eram angolanos do interior que se utilizaram das reduzidas possibilidades de ascensão social criadas pelo Estatuto do Indigenato (1926-1961) para constituírem-se enquanto uma elite letrada dentro de Luanda. Não se viam nem atuavam como grupo, apesar de possuírem elementos em comum, como a origem rural, serem "pretos", terem adquirido escolaridade formal nas missões religiosas (sobretudo, protestantes) e o fato de não terem vínculos familiares, como as elites crioulas existentes em Luanda, os "antigos assimilados". Por conta dessa diferença em relação aos crioulos, foram denominados pela historiografia relativa a Angola como "novos assimilado","

Os "novos assimilados" tiveram sua formação ligada majoritariamente às missões protestantes, que faziam parte do incipiente sistema de ensino existente em Angola, constituindo-se uma porta de entrada para o mundo dos brancos. Conceição Neto (2008) assevera que, em Angola e em outras regiões do continente africano, tais missões foram responsáveis pelo surgimento de elites letradas, social e culturalmente influenciadas pela cultura cristã e ocidental.

O mapa da escolarização das populações rurais seguia o mapa da distribuição das missões pelo território angolano. Assim, em zonas de forte presença missionária, como Huambo, Cabinda e Uíje, o grau de escolarização e também o número de assimilados era maior; já no sul e leste angolano, com fraca presença das missões, o resultado era inverso.

Sobre a vivência dos angolanos nas escolas construídas pelas missões cristãs, discutiremos a seguir a partir do estudo das memórias de militantes políticos e escritores como Uanhenga Xitu (1984, 1991 e 2006), Adriano Sebastião (1993), Raul David (1991), Amélia de Fátima Cardoso (2006) e Manuel Pacavira (1981 e 2012) ${ }^{17}$.

Estas memórias podem ser entendidas à luz da teoria de Paul Ricoeur (2007), em uma relação dialógica entre o eu (memória individual), os próximos (memória compartilhada com sua geração) e os outros (memória coletiva, social, pública).

Compuseram-se de entrevistas e autobiografias, visando construir referências discursivas que tivessem uma validade ampla e pudessem formar temporalidades ancoradas do presente no passado, buscando, nesse passado, "origens", "começos", a partir dos quais seria definida uma trajetória e construída redes de significações e sentidos e justificativas para as ações tomadas. Para Jacques Le Goff (1996), “[...] a memória é um elemento essencial do que se costuma chamar identidade, individual ou coletiva, cuja busca é uma das atividades fundamentais dos indivíduos e das sociedades de hoje, na febre e na angústia" (LE GOFF, 1996, p. 476).

Nestes relatos memorialísticos há uma grande primazia do narrador, na condição de portador de uma memória a partir da qual são constituídas suas identidades. Nesse sentido, é importante destacar Walter Benjamim (1994), para quem o narrador retira da experiência o que conta, ou seja, de sua própria experiência ou a relatada pelos outros e incorpora as coisas narradas à experiência dos seus ouvintes, construindo não só sua identidade, mas, também, uma identidade coletiva ${ }^{18}$.

\section{O acesso à educação formal no interior angolano.}

$\mathrm{O}$ interior angolano de meados do século XX foi marcado pela implantação de uma série de culturas agrícolas obrigatórias, como o algodão e o café. A imposição do 
plantio de tais gêneros agrícolas tornou ainda mais difícil a vida dos camponeses angolanos, forçados a abandonar o cultivo de gêneros alimentares e submetidos a uma situação de vulnerabilidade ainda maior em momentos de grande fome.

A distribuição desses produtos era irregular no território angolano, com uma estiagem de maior densidade no norte. Dessa região, sobretudo das províncias de Ícolo e Bengo, Golungo Alto, Malanje e Catete, saíram muitos daqueles que viriam a ser os "novos assimilados", ou seja, os personagens que na primeira metade do século XX terão acesso à educação escolar através das missões. $\mathrm{O}$ militante político e escritor Uanhenga Xitu (2006), da região de Icolo e Bengo, em depoimento dado a Dalila Mateus (2006), fala das dificuldades por ele vivenciadas para ter acesso à escola. ${ }^{19}$ :

$\mathrm{Na}$ situação social em que vivíamos, em que vivia o Indígena, melhor dizendo, o Preto, nas dificuldades que encontrava para entrar no liceu, para obter o bilhete de identidade, para ser assimilado, foram tantas as dificuldades, que vi nos lugares por onde passei, que comecei a tirar notas (XITU apud MATEUS, 2006, p.10).

Na fala de Xitu (2006), notamos a associação do preto com o indígena e a diferenciação destes em relação ao assimilado. Ir para a escola significava a possibilidade de mudar de estatuto racial (preto) e social (indígena) para uma posição, em tese, mais favorável. Nesse sentido, Homi Bhabha (1998), ao fazer uma discussão sobre os locais da cultura e argumentar sobre os "entre-lugares" que são produzidos na articulação de diferenças culturais e sociais, no caso ao qual estamos analisando, o "indígena" e o "preto", nos ajuda a entender estes dois conceitos como "[...] estratégias de subjetivação singular ou coletiva - que dão início a novos signos de identidade e postos inovadores de colaboração e contestação, no ato de definir a própria ideia de sociedade" (BHABHA, 1998, p. 20).

O pagamento da mensalidade escolar trazia grandes dificuldades para os alunos, como narrou o militante político Adriano Sebastião $(1993)^{20}$ :

Pagava-se mensalmente 2,50 (dois angolares e meio) e essa quantia, às vezes minha mãe não tinha e eu para pagar a mensalidade tinha de trabalhar na lavra da missão, na enxada, uma thonga medida pelo professor Katolongo que consistia numa distância de 4 (quatro) metros de largura por 20 e 25 metros de comprimento. Esta medida variava conforme a densidade do capim da área a limpar [...] muitos não chegavam a acabar essa empreitada. Nós sempre acabamos e por isso merecemos sempre o respeito do casal professor e até de alguns colegas (SEBASTIÃO, 1993, p. 31).

O angolar foi a moeda de Angola de 1928 a 1953; e os dois angolares e meio a que fez referência era uma cédula única que correspondia à segunda menor cédula então existente. Apesar disso, a pobreza era de tal ordem que esse valor era difícil ser pago. Outra questão destacada em seu depoimento é que, mesmo estando na escola, o uso do trabalho forçado permanecia como traço comum nas relações entre portugueses e africanos; para tanto, os portugueses utilizavam-se das brechas deixadas pelo Estatuto do Indigenato de 1926. Sebastião também se refere à importância dessas escolas missionárias para a educação dos angolanos:

Sem receio de desmentido o Kalomboloca aqui falado podia ser considerado a capital do Concelho embora essa estivesse localizada em 
Catete. E porque dizemos isso, dizemo-lo porque foi em Kalomboloca em Cavula onde se instalou a $1^{\mathrm{a}}$ Missão, a Igreja, o Evangelho, trazido pelo inesquecível Robert Shields e com o seu pastor primeiro o senhor José Paulino em 1885, que não só espalhou a doutrina evangélica a toda área de Ícolo e Bengo (Catete) como trouxe consigo a Escola em que saíram professores como Domingos Pedro Cardoso, Aurélio da Silva Coimbra, Adão Gaspar Domingos, Agostinho Pedro Neto que fizeram discípulos como Cristóvão Agostinho de Carvalho, Júlio João Miguel, Cristóvão Manuel da Costa e muitos outros (SEBASTIÃO, 1993, p. 29).

Em sua fala, há referência a duas gerações de missionários e professores metodistas: uma primeira geração de fins do século XIX, em que se encontravam Robert Shields e Domingos Pedro Cardoso, que apareceram na sexta edição do jornal da West Central África Mission Conference, de 1909, como membros importantes da organização interna da missão metodista de Malanje ${ }^{21}$; e a segunda geração de professores da primeira metade do século XX, como Cristóvão Agostinho de Carvalho e Júlio João Miguel. Sebastião tentou mostrar a longevidade e importância histórica dessa missão em Angola. Continuou ele ressaltando a importância desse espaço:

Da escola de Ícolo e Bengo trazida pela igreja saíram muitos filhos que com os olhos já abertos e formados que nos nossos dias chamaríamos de complot, recusaram-se ao humilhante trabalho de cultura obrigatória do algodão que foi considerado, pelos comerciantes da região, liderados por Zé dia Mbala (José Bernardo), o mais destacado da área, como revolta e como resultado ou consequência a convocação da força do exército da $1^{a}$ linha estacionada no Catete que fez uma série de prisões dos considerados 'cabecilhas' que foram deportados para S. Tomé em 1922 (SEBASTIÃO, 1993, p. 22).

Para Sebastião (1993), Ícolo e Bengo era uma região de onde saíram muitos combatentes da luta contra Portugal e, por isso, as pessoas eram muito malvistas pelos metropolitanos, como podemos perceber, por exemplo, no conto VavóXíxi e seu neto Zeca Santos, de Luandino Vieira, a ser analisado posteriormente.

Sebastião (1993) considera, de alguma forma e mesmo que inconsciente, a existência dessas escolas como motivadoras das ações reivindicativas dos angolanos. Essas ações fizeram parte de uma série de resistências a Portugal na primeira metade do século $\mathrm{XX}$, provocadas pela intensificação do trabalho forçado das populações locais e $\mathrm{o}$ cerceamento social e econômico dos nativos.

Nesse contexto, aconteceram a revolta dos Bakongos (1913-1915), a revolta de Kwanza Norte (1916-1917) e a revolta do Catete (1922), à qual Sebastião se refere, e uma série de outras manifestações contra o trabalho forçado, que ocorreram entre 1922 e 1925 na área compreendida entre Malange e Luanda. José Adão Fragoso, em seu livro de memórias (2010), relata que seu pai Adão José Fragoso também participara da revolta de 1922 como um dos líderes desse evento, mais tarde deportado para São Tomé ${ }^{22}$.

Acompanhando a história de Sebastião (1993), notamos que sua entrada no seminário protestante ocorreu para evitar complicações decorrentes da fuga dos campos de algodão, onde trabalhava de maneira forçada:

É que ela [a mãe de Sebastião] sabia que os que andavam na escola da missão quer católica como evangélica [protestante] não eram mexidos pelos kimbares e como ela não mais queria que o seu único filho, alguma 
vez mais fosse contratado para qualquer serviço do Estado, fez tudo para me entregar nas mãos de um protetor - a missão - pelo que coube essa honra ao casal Katolongo (SEBASTIÃO, 1993, p. 29).

Em seu depoimento, ele reforçou uma ideia que aparece em outros momentos de sua fala, ou seja, a missão constituía um território livre das ações do governo português e funcionava como uma fuga para as situações de discriminação social e racial, vivenciadas diariamente pelos angolanos. Sobre a entrada na missão protestante, afirmou:

[...] minha mãe pegou em mim e me levou à missão Evangélica e me entregou nas mãos do Professor e Pastor, o venerando Cristóvão Agostinho de Carvalho e sua esposa, a senhora D. Maria Diogo da Silva de Carvalho, com a recomendação de fazerem de mim o que quisessem e pudessem (SEBASTIÃO, 1993, p. 28).

O desespero em sair daquela vida fez com que sua mãe pedisse aos professores que fizessem de seu filho o que "quisessem e pudessem". Quanto ao professor Cristóvão de Carvalho, ele foi um dos mais importantes missionários da Igreja Metodista de Angola. Em 1965 transferiu-se do Bengo para Luanda, onde se tornou o primeiro reverendo da Igreja Metodista da comunidade de Belém, no Bairro Rangel, até hoje existente ${ }^{23}$. Continuou Sebastião (1993):

Vestido de Kihamba, como camisa, de um calção de cotim e de quedes sem nenhum livro na mão, assim me apresentei porque assim minha mãe me levou e me entregou nas mãos do casal de professores Cristóvão de Carvalho - Katolongo - e Maria Diogo de Carvalho, em 1936 (SEBASTIÃO, 1993, p. 29).

Vestido como um trepador de $\operatorname{cocos}^{24}$, sem nenhum instrumento de saber europeu (o livro) na mão, ele foi levado por sua mãe para se apresentar aos professores, vistos por ela como instrumento de transformação. Em uma sociedade marcada pela matriarcalidade, onde o filho mantém um contato estreito com a mãe por toda a vida, o que, no sentido simbólico, permite dizer que o cordão umbilical nunca é inteiramente cortado, pois ele sempre continuará dependente da linhagem dela, a mãe de Sebastião assumiu o papel de progenitora e protetora do filho ${ }^{25}$.

Segundo Donizeth Santos (2007), na literatura angolana, o tema mãe e, em particular, mãe África é bastante recorrente. Segundo ele, esse "canto à Mãe-África" tornou-se, desde a primeira citação dessa expressão no romance NgaMuturi, de Alfredo Troni, de 1882, um "[...] grito de afirmação da identidade angolana (angolanidade) e africana (africanidade), resgatando o elemento ancestral africano acobertado pela assimilação cultural europeia promovida pelo colonialismo" (SANTOS, 2007, p.28).

Xitu (1991), primo e colega de Adriano Sebastião, que, em Colomboloca, também foi entregue por sua mãe para a mesma missão protestante, disse que essas missões eram mais "abertas" às ideias nacionalistas, não eram subsidiadas pelo governo e atraíam a população angolana para suas escolas e centros de saúde. No depoimento dado a Laban (1991), buscou explicar esta sua impressão:

[...] ensinavam a ler e escrever já com uma dosezinha de angolanismo, para a identificação própria do angolano. Eu senti isso na escola, quando era aluno. Por exemplo, os professores contavam as suas histórias... Há uma lição, hoje, de História, ele vai contando, o Diogo Cão, Bartolomeu 
Dias, porque a história de Angola pouco ou nada existiu: havia umas linhazinhas pequenininhas, que nem se davam. Mas explicavam o desembarque do Diogo Cão, ao mesmo tempo que também enaltecia o poder dos angolanos - por exemplo, a rainha Jinga ao encontro com os portugueses, o Salvador Correia... Ora, fazer a vez de professor oficial das missões protestantes - a maior parte eram negros angolanos - e ao mesmo tempo explicava e enaltecia as qualidades dos guerrilheiros angolanos. Portanto, é isso que eu via como diferença. E isso não era um caso isolado, eram quase todos os professores. Falava-se dos reis do Congo, Ndunduma, Mandume, etc., etc... (XITU In: LABAN, 1991, p. 125).

Ele se refere a "angolanismo" como sinônimo de nacionalismo. O termo "angolanismo" (ou "angolanidade"), um dos neologismos criados pelos nacionalistas angolanos durante o processo de luta anticolonial ${ }^{26}$, aparece, inicialmente, em um artigo de Fernando Costa Andrade, que o define como sendo o instrumento do homem angolano em "[...] luta contra os processos erosivos da alienação" (ANDRADE apud Jorge, 1988, p. 6). Entretanto, tal visão ainda apresentava certo esquematismo e ortodoxia por pensar a cultura de maneira estática, por isso Alfredo Margarido (1960) foi quem melhor o definiu, ao dizer que a angolanidade se refere à "substância nacional angolana".

No domínio político, a angolanidade tornou-se um instrumento para a criação e afirmação de uma identidade nacional e, no aspecto cultural, serviu como um contraponto à política de assimilação colonial, ao propor certo "retorno às origens" e uma rejeição à imposição cultural portuguesa ${ }^{27}$, o que, segundo Xitu (1991), acontecia dentro dos espaços escolares das missões protestantes, sobretudo porque alguns professores eram "pretos" angolanos que ensinavam a "grandeza" da história de Angola. Ao ser perguntado por Laban (1991) porque sua mãe o colocara em uma missão protestante, respondeu:

A missão protestante foi a mais acolhedora. Independentemente disso, foi a primeira missão que apareceu naquele lugar. E mais fez pelo povo do que a missão católica que já tinha lá as igrejas há séculos. Uma história por exemplo: na Muxima, Quiçama - já ouviu falar? O povo de Quiçama ficou quase completamente analfabeto. Só depois de uma determinada época é que começou a despertar. Um ou outro que se safou, que os missionários enviaram para os seminários, aprendeu qualquer coisa... mas $90 \%$ da população ficou quase analfabeta... A igreja lá estava há séculos. E o ensino das populações estava entregue à missão católica. Ora, quando a missão protestante entra, muito mais tarde - já pelos anos de 30 -, deu um passo qualitativo nas populações. Eis uma das razões pelas quais se notou, no passado, a diferença onde está uma missão católica e uma missão protestante. Isso notou-se muito, sobretudo no Centro e no Sul de Angola (XITU In: LABAN, 1991, p. 125).

Xitu considera a missão protestante como mais "acolhedora", a que "mais fez pelo povo", em especial, quanto ao processo de alfabetização dos angolanos, reconhecendo uma diferença qualitativa entre as regiões de presença católica e as de presença protestante. Entretanto, como já dissemos, é preciso ponderar que, tanto as missões católicas, quanto as protestantes impuseram lógicas culturais europeias, entretanto, como em todo contexto que envolve violência e resistência, os angolanos utilizaram-se das poucas brechas deixadas pela educação para resistir ao colonialismo português, ressignificando e criando novas subjetivações. 
Seu depoimento nos ajuda a pensar o caráter controverso e complexo do contato com o universo europeu, que poderia significar o afastamento da chamada cultura tradicional, ou seja, a "cultura dos mais velhos":

Porque cresci e fui educado nas igrejas e nunca me dediquei a tradições que se chamavam "obscuras", segundo uns, ou dessa ou daquela religião "obscura", no dizer dos outros. Porque as únicas religiões que não eram obscuras e se conheciam por doutrinas científicas: católica ou protestante (XITU In: LABAN, 1991, p. 116).

Ele faz uma distinção entre as tradições religiosas "obscuras" e as "científicas", utilizando para isso o parâmetro europeu. Tendemos a imaginar que a utilização de tal parâmetro deveu-se, provavelmente, ao fato de que a entrevista estava sendo dada para um francês, Michel Laban, apesar de não ter voltado a esta distinção em nenhuma outra entrevista analisada por nós ${ }^{28}$. Em um depoimento dado anos antes, em 1984, afirmou que esse afastamento se dava especialmente por conta dos assuntos que eram lecionados na escola:

No meu tempo sabia-se mais de Portugal, 'mãe-Pátria', dos rios, e seus afluentes e foz, divisão administrativa do Minho ao Algarve, limites, suas guerras, façanhas portuguesas, mas de Angola nem se sabia sequer o que existia na região. Os professores recordavam-nos, no antigamente, as histórias dos escritores portugueses como Camilo Castelo Branco, Ramalho Ortigão, Júlio Dinis, Eça de Queirós etc. (XITU, 1984, p. 184).

Era uma escola de portugueses para portugueses, a cultura local era completamente desconsiderada. Na apresentação do livro Os discursos do "mestre Tamoda" (1984), Xitu (1984) utiliza-se de seu personagem para lembrar as escolas do período colonial:

Muitas vezes fizeram-me a pergunta por que os alunos gostavam mais dos ensinamentos do Mestre Tamoda que dos professores oficiais. Os alunos gostavam mais do método do ensino de Tamoda porque pensavam que se aprendia com mais facilidade de poder discutir-se com qualquer estudante ou professor (XITU, 1984, p. 20).

$\mathrm{Na}$ "educação de Tamoda", ou seja, na educação de angolanos para angolanos, idealizada por Xitu, diferentemente da educação à portuguesa, em que somente o professor falava, havia uma dialogicidade entre alunos e professores, conferiam-se palavra e autonomia ao angolano. Era também uma educação sem castigos corporais:

Além disso, Tamoda não dava palmatoadas nem chicotes a ponto de fazer desmaiar o aluno, como o faziam alguns professores do ensino oficial, nem tão-pouco os mandava trabalhar nas lavras na tal $5^{\text {a }}$ (quinta-feira), dia de serviço do senhor professor, sem água, nem comida; nem os mandava galgar a 20 a 50 quilômetros da sanzala à procura ou à compra de peixe e outros produtos; nem às lavras dos comerciantes apanhar algodão, e o pago, o lucro, revertido a favor do professor, para compensar a mesada que os pais pagavam (XITU, 1984, p. 20). 
Essa ligação com o universo português foi também destacada por Raul David $(1991)^{29}$ na entrevista realizada em 1988, em Luanda, inicialmente, sobre temas vinculados à sua produção literária. A primeira questão de Laban (1991) girava em torno do livro Colonizados e Colonizadores, mas, depois, o entrevistado acabou por conduzir, em grande parte, a conversa, utilizando-a para contar sua história, o fato de ter sido um assimilado e as complexidades dessa condição $\operatorname{social}^{30}$. Sobre a ligação com o universo português recorda:

Eu fui educado num meio fechado. Minha madrinha, que era professora particular, ensinou-me a falar e a escrever em termos dela - era lisboeta, ainda por cima... Saio de casa de minha madrinha, vou para um seminário e vou encontrar os padres do Espírito Santo que fazem questão de serem puritanos de linguagem. Logo, eu, para escrever, para fazer as descrições, para traduzir o clássico latim... Tivemos um padre francês, o Emile Blanc, que falava português e tal e qual como o professor está a falar, era exigente na correção de linguagem e não só de linguagem como de ortografia, caligrafia inclusivamente, e essa exigência deu-nos a faculdade de chegarmos cá fora e podermos entrar no comércio, trabalharmos, sermos polivalentes: podermos trabalhar em todos os setores da vida devido às qualidades fortes que eles nos deram (DAVID apud LABAN, 1991, p. 51).

Em 1866, padres ligados à Congregação do Espírito Santo partiram de Portugal em direção a Angola, onde se dividiram, a princípio, em quatro circunscrições missionárias: Cabinda, Malange-Lunda, Planalto de Benguela e Planalto de Huíla ${ }^{31}$.

\section{As distinções entre as escolas católicas e protestantes.}

Outro fato que aparece nas memórias daqueles que frequentaram a escola colonial é a distinção entre a escola católica e a protestante, o que está muito presente, por exemplo, no depoimento dado por David (1991):

O primeiro missionário que chegou cá humanizou-se como o povo que ele encontrou - estudou o meio. A primeira coisa que ele fez foi acarinhar as crianças... E como há aquela expressão bem portuguesa que diz: 'Quem meus filhos beija, minha boca adoça...', os pretos disseram assim: 'Este branco é diferente dos outros. Os outros trazem aguardente para vender, trazem panos para vender, trazem espingardas para matar... (DAVID In: LABAN, 1991, p. 60).

Sua fala em muito se aproxima da de Xitu (1991), pois descreve os missionários protestantes como mais "humanizados", comportando-se de maneira diferente dos outros brancos. David (1991) acentuou ainda mais a crítica aos missionários católicos, sobretudo aqueles nascidos em Portugal:

E a prática até ensinou o seguinte: os missionários franceses, holandeses, italianos, belgas, que nós conhecemos, vinham de famílias tradicionalmente ricas - chegavam ao $3^{\circ}$ ano de Engenharia, ao $3^{\circ}$ ano de Direito - como eles eram católicos convictos diziam aos paizinhos ' $\mathrm{Eu}$ não acabo mais, vou para o seminário, vou ser padre...' E esses meninos 
quando para cá vieram, portaram-se como missionários de elite, portaram-se com dignidade... Enquanto que o padre português, sabe, ele vinha de uma família empobrecida, um campônio - os camponeses naquelas terras aldeias têm dez, doze filhos... E então, o pároco para aliviar o seu paroquiano de tanta pobreza, tirava-lhe dois filhos ou três que mandava para o seminário. Ora, esses homens não têm formação moral para virem cá. Eles vêm com o espírito colonizador (DAVID In: LABAN, 1991, p.59).

Para David (1991), faltava aos portugueses que iam para a colônia um sentimento religioso nobre, eles não tinham "moral" para o processo de evangelização; para eles ir para Angola significava uma possibilidade de mudança de vida. De acordo com dados coletados por Dulley (2010) sobre Huambo, então denominada pelos portugueses como Nova Lisboa, entre os anos de 1955 e 1960, trabalharam na missão católica 140 padres, cuja imensa maioria era composta de portugueses, ou seja, 105, além de 04 franceses, 12 holandeses, 12 suíços e 07 espanhóis ${ }^{32}$. Esta suposta "deturpação" moral dos portugueses fazia com que, mesmo religiosos, eles reproduzissem o racismo praticado pela metrópole:

Os seminaristas negros saídos dos seminários nunca tinham proteção -
negros ou mulatos -, mas os seminaristas brancos, mesmo que tivessem
passado pelo seminário uma semana só, eram protegidos [...] os padres
brancos ganhavam um ordenado x, os padres pretos ganhavam 300
angolares, ou 300 escudos! Será possível que um homem licenciado em
Filosofia e Teologia vá ganhar 300 mil réis? Será humano isso? Que
crédito podem eles ter? Por isso é que eles são acusados de distorções
sociais e não tem defesa (DAVID In: LABAN, 1991, p. 61).

David (1991) fez questão de enfatizar que a discriminação racial e a cisão branco versus preto suplantavam a questão religiosa. Ao mesmo tempo, para fazer um contraponto com a proteção conseguida nas missões protestantes, afirmou que aqueles que procuravam a missão católica como uma forma de proteger-se do sistema colonial, com o tempo, não encontravam proteção alguma.

Desses personagens analisados, poucos foram tão contundentes na crítica às missões religiosas quanto Amélia de Fátima Cardoso ${ }^{33}$, sob o pseudônimo literário Dya Kasembe, em seu livro As mulheres honradas e insubmissas de Angola (2006). O livro entrelaça elementos das tradições orais do Bengo com relatos memorialísticos pessoais.

Cardoso (2006) nasceu na região de Muxima em 1946, um dos primeiros lugares ocupados e colonizados pelos portugueses. Com pouco mais de três anos foi entregue a uma missão católica, passando mais tarde a estudar no Colégio São José de Cluny, em Luanda. Ela retrata sua formação escolar com uma forte carga de dramaticidade e dor. Ao que nos parece, o objetivo do livro foi, de alguma forma, "purgar" os processos de assimilação aos quais estivera submetida. Para entender seu depoimento, nos valemos das análises de Claudine Haroche (2001), para quem toda memória é, de alguma forma, sempre uma reconstrução engajada do passado, que leva a um processo de reconstrução de identidades a partir das quais se reivindica o direito ao reconhecimento ${ }^{34}$.

Depois de destacar questões ligadas às tradições das mulheres em sua zona de origem, ela afirma que não teve infância, pois “[...] aos três anos fui tirada, arrancada do seio materno e levada para longe dela, qualificada como indígena iletrada. Não podia educar-me, morri aos três anos..." (KASEMBE, 2013). A presença de missões católicas em 
sua terra natal fez com que uma série de tradições fosse desaparecendo por força da "educação civilizadora" praticada pelos portugueses:

\begin{abstract}
Essa educação - civilizadora - deveria começar pelo baptismo para nos tirar segundo eles a 'mukila', símbolo do bantu, ou seja, do negro no seu estado selvagem. E tentavam convencer-nos que todo aquele que não fosse batizado, a 'mukila' não parava de crescer. Esse ritual do batismo, que consistia em uns grãos de sal na boca e uma concha de água na cabeça, fazia rir os sábios do círculo da Nganga e por preço nenhum eles seria ridicularizados dessa maneira. A recusa deles foi-lhes fatal. Passavam a vida a fugir desse batismo que os destituía de toda autoridade, mudava-lhes o nome e tirava-lhes a identidade, sem contar a perda dos poderes seculares. Assim, muitos morreram outros desapareciam nas matas e viveram anônimos sem terras, eles que eram os senhores de terras (KASEMBE, 2006, p. 79).
\end{abstract}

Segunda ela, a imposição do batismo visava acabar com a aristocracia nativa e suas estruturas político-religiosas. Em sentido contrário, outro "novo assimilado", Manuel Pacavira (1981), na introdução de seu livro Gentes do Mato, relatou sua vivência em um colégio católico e de que maneira isto o ajudou a ter mais "esclarecimentos" sobre o mundo colonial:

Já como estudante no Colégio da Casa das Beiras, íamo-nos preocupando por encontrar mais meios para nos esclarecermos, para nos cultivarmos e despertar politicamente outros rapazes da nossa idade, e não só. Alargámos a esfera das nossas relações. Tínhamos contactos com os mais velhos da "missão", antigos seminaristas, padres, dentre os mais, o falecido Cônego Manuel Joaquim Mendes das Neves; e outros intelectuais (PACAVIRA, 1981a, p.12).

O cônego Manuel das Neves, ao qual se refere Pacavira (1981), um mestiço nascido no Golungo Alto a 25 de Janeiro de 1896, foi um dos principais nomes do movimento anticolonialista angolano, responsável pela formação do grupo União dos Povos Angolanos (UPA), no bairro Sambizanga, em 1958, além de ter sido um dos incentivadores da rebelião de 4 de fevereiro de 1961, que deu início à luta armada contra Portugal.

No seu livro de memórias, José Adão Fragoso (2011) relatou que, no Colégio da Casa das Beiras, no qual Pacavira estudou, conheceu Nito Alves, um dos mais importantes agentes políticos angolanos, com quem iniciou a luta clandestina, além de outros companheiros: Eduardo Pitra, Mateus Nhanga, Tito, João Pedro ${ }^{35}$.

Pacavira (1981) tenta mostrar ao leitor a formação libertária dentro do espaço escolar. Já na entrevista de 2012, voltou a tocar na questão relativa a seu universo educacional, em que a escola surgiu como uma espécie de esconderijo ou fuga das situações de exploração colonial, tal como se referiu Sebastião:

Estudávamos somente por estudar, sem consciência e perspectiva de nação, porque éramos colonizados, ainda não tínhamos idade de pensar numa pátria livre e independente. Estudava-se para se atingir um determinado nível de escolaridade, que nos permitisse, pelo menos, um estatuto susceptível de nos libertarmos do "imposto indígena" e 
subsequentemente do contrato, para o trabalho forçado nas roças do colono português (PACAVIRA In: CRISTOVÃO, 2012).

Em um contexto mais recente (2012), o depoimento dele denota um grande pragmatismo em relação ao acesso a escola. Denotando assim os impactos do contexto contemporâneo angolano, no qual aqueles que conseguiram alguma ascensão social passaram a ocupar cargos no governo do país angolano, tendo uma posição mais pragmática e menos idealista nesta Angola pós-independência.

\section{Considerações finais}

A escola era uma das poucas possibilidades de ascensão social para o angolano. Era uma forma de se livrar do trabalho forçado, dos impostos e da violência da administração colonial. Se por um lado significava a desestruturação das lógicas culturais daqueles angolanos que faziam parte dela, trazendo a conversão ao cristianismo por parte daqueles que frequentaram as escolas das missões religiosas, por outro também o espaço em que um conhecimento mais qualificado da realidade social de Angola começava a circular e onde se formara uma elite política que irá conduzir Angola a independência em relação a Portugal.

\section{Referências}

\section{Fontes}

CARDOSO, Boaventura. Prefácio a $1^{\mathrm{a}}$ Edição In DAVID, Raul. Escamoteados na Lei. União, Endiama, Porto do Lobito. 1990 Morreu escritor angolano Raul David, autor de "Colonizados e Colonizadores" Agência LUSA. 21 Fev, 2005, 11:28. Disponivel em http://www.rtp.pt/noticias/index.php?article=153039\&tm=4\&layout=121\&visual=49.

CALONGO, Carlos. Comunidade do Rangel com mais um ano de vida. Jornal de Angola, 16 de Setembro de 2010. Disponível em http://jornaldeangola.sapo.ao/18/0/ comunidade_do_rangel_com_mais_um_ano_de_vida. Acesso em $10 \mathrm{de}$ Agosto de 2012 .

DAVID, Raúl. Entrevista In: LABAN, Michel. Angola: encontro com escritores. Porto: Fundação Eng. António de Almeida, 1991. - p. 45-76

LABAN, Michel. Angola: encontro com escritores. Porto: Fundação Eng. António de Almeida, 1991 (Volume I e II).

KASEMBE, Dya. As mulheres honradas e insubmissas de Angola. Luanda: Nzila, 2005

FRAGOSO, José Adão. O Meu Testemunho. Edição do autor. Luanda, 2010.

PACAVIRA, Manuel Pedro. Introdução In; PACAVIRA, Manuel Pedro. Gentes do Mato. Lisboa, Edições 70, 1981. 
Escrevo quando sinto necessidade de contar uma história. Entrevista dada a Aguinaldo Cristóvão. União dos Escritores Angolanos, 2012. Disponível em http://www.ueangola.com/entrevistas/item/430-escrevo-quando-sinto-necessidade-decontar-uma-hist\%C3\%B3ria-verdadeira.Acesso em 08 de Fevereiro de 2013.

SANTOS, Arnaldo. A Casa velha das margens. Luanda. Edições Maianga, 2004.

SEBASTIAO, Adriano. Dos campos de algodão aos dias de hoje. Edição do Autor, 1993

XITU, Uanhenga. Entrevista In: LABAN, Michel. Angola: encontro com escritores. Porto: Fundação Eng. António de Almeida, 1991. - p. 109-131 Entrevista In: MATEUS, Dalila Cabrita. Memórias do Colonialismo e da Guerra, Porto, Edições ASA, 2006.

Entrevista In: CRISTÓVÃO, Aguinaldo Cristóvão e CORI, Isaquiel. Pessoas com quem conversar. Angola, UEA, 2004

Palestra proferida pelo autor em 25 de Agosto de 1983, aos estudantes de literatura africana, e patrocinada pelo centro de estudos africanos e pela disciplina de literatura africana do departamento de línguas vernáculas da Faculdade de Filosofia Letras e Ciências Humanas da Universidade de São Paulo, Brasil In: XITU, Uanhenga. Os discursos do "mestre" tamoda. Luanda, Angola: União dos Escritores Angolanos, INALD, 1984.

\section{Artigos e Livros}

BENJAMIN, Walter. O Narrador: considerações sobre a obra de Nikolai Leskov. In: Magia e técnica, arte e política: ensaios sobre literatura e história da cultura. São Paulo: Brasiliense, 1994, p. 197-221.

BOAHEN, Albert Adu. Tendências e processos novos na África do século XIX In: AJAYI, J. F. Ade. História Geral da África VI. Brasília, Unesco, 2010.

CONCEIÇÃO NETO, Maria Eugênia. Breve Introdução histórica In: MEDINA, Maria do Carmo: Processos políticos da luta pela independência. Luanda: Faculdade de Direito UAN 2003:

Ideologias, Contradições e Mistificações da Colonização de Angola no. Século XX. In: Lusotopie. Éditions Karthala, 1997.

DULLEY, Iracema. Deus é feiticeiro - prática e disputa nas missões católicas em Angola colonial. São Paulo: Annablume. 2010, p.34.

FREUDENTHAL, Aida Faria. Angola. In: MARQUES, A. H. de Oliveira. Nova história da expansão portuguesa, V. XI, Lisboa: Estampa, 2001.

GABRIEL, Manuel Nunes. Angola. Cinco séculos de Cristianismo. Edição Liberal, Braga, 1978.

HENDERSON, Lawrence W. A Igreja em Angola: um rio com várias correntes. Lisboa: Além-Mar, 1990, 
HAROCHE, Claudine. Les exigences de la reconnaissance dans les sociétés démocratiques" In ENRIQUEZ (Edit) Le Goût de l'altérité, Paris, Desclée de Brouwer, 1999.

HAMPATÉ BÂ, A. A tradição viva. In: KI-ZERBO (coord.). História Geral da África I. Metodologia e pré-história da África. São Paulo: Ática; Paris: UNESCO, 2012, pp.181218.

HALBWACHS, Maurice. A memória coletiva. São Paulo: Centauro, 2004

LE GOFF, Jacques. Memória, In: História e memória, pp. 423-483, Ed. da Unicamp, Campinas, 1982.

KAVAYA, Martinho. Educação, cultura e cultura do amém: Diálogos do Ondjango com Freyre em Ganda / Benguela / ANGOLA. Mestrado em Educação. Universidade Federal de Pelotas, 2006

JORGE, Manuel. Nação, identidade e unidade nacional em Angola. In Latitudes: Cahiers Lusophones, France, 2006, p. 3-10

Para Compreender Angola, Lisboa: Dom Quixote, 2008, 296p.

MARTINS, Maria Odete Soares - O pensamento missionário do padre Joaquim Alves Correia (1886-1951). Lusitania Sacra. Lisboa, 2007-2008.

MARQUES, A. H. de Oliveira. Nova história da expansão portuguesa. Volume XI, Lisboa: Estampa, 2001.

MARQUES, Inácio Luiz. As memórias do 27 de maio de 1977 em Angola. Anais do XXVI Simpósio Nacional de História - ANPUH • São Paulo, julho 2011.

MESSIANT, Christine. L'Angola post-colonial: Sociologie d'une oléocratie, Paris: Karthala, 2009.

. "Luanda (1945-1961): colonisés, société coloniale et engagement nationaliste", in Michel Cahen (Org. de). Vilas et cidades. Bourgs et villes en Afrique Lusophone. Paris: Laboratoire Tiers-Monde/Afrique, 1989.

"Angola: the challenge of statehood", in David Birmingham; Phyllis M. Martin (Ed. by).History of Central Africa.The Contemporary Years Since 1960.London: Longman, 1998.

'Protestantismes en situation coloniale. Quelles marges?', Lusotopie 245-256.1998

MUNANGA, Kabengele. Os Basanga de Shaba, Um Grupo Etnico do Zaire. São Paulo: FFLCH/USP, 1986. 334 p. 1995/1996.

Origem e Histórico do Quilombo na África. Revista USP v. 28, p. 56-64, 
NASCIMENTO, Washington Santos. Gentes do Mato: os "novos assimilados" em Luanda. Tese de Doutorado. Faculdade de Filosofia Letras e Ciências Humanas da Universidade de São Paulo, São Paulo, 2013.

NEVES, António M. S. S. "As Igrejas e o nacionalismo em Angola", Revista Lusófona de Ciência das Religiões, 13-14: 511 - 526, 2008.

RICOEUR, Paul. A memória, a história, o esquecimento. Campinas/SP: Editora da Unicamp, 2007.

THOMAZ, Omar Ribeiro. O bom povo português: usos e costumes d'aquém e d'além mar, 04/2001, Mana (Rio de janeiro), Vol. 1, pp.55-88, Rio de Janeiro, 2001.

TOMAS, Cláudio Discursos e práticas alternativas de reconciliação nacional e de construção da nação em Angola: O caso da Igreja Evangélica Congregacional de Angola. Dissertação de mestrado, Lisboa: ISCTE- Instituto Universitário de Lisboa, 2009.

PORTELLI, Alessandro. Forma e significado na História Oral: a pesquisa como um experimento em igualdade. Projeto História, v. 14, p. 7-24, fev. 1997

\section{Notas}

" Doutor em História Social pela Universidade de São Paulo (USP). Mestre em Ciências Sociais pela Pontifícia Universidade Católica de São Paulo (PUC-SP) e licenciado em História pela Universidade Estadual do Sudoeste da Bahia. E-mail: washingtonprof@gmail.com

${ }^{1}$ Albert Adu Boahen (2010) no capítulo 3 "Tendências e processos novos na África do século XIX" da "História Geral da África VI" constrói um amplo painel no qual destaca o impacto, sobretudo no século XIX, da presença muçulmana e cristã no continente africano. BOAHEN, Albert Adu. Tendências e processos novos na África do século XIX In: AJAYI, J. F. Ade. História Geral da África VI. Brasília, Unesco, 2010.

${ }^{2}$ CONCEIÇÃ̃O NETO, Maria Eugênia. Breve Introdução histórica In: MEDINA, Maria do Carmo: Processos políticos da luta pela independência. Luanda: Faculdade de Direito UAN 2003: p.7.

3 "O artigo $6^{\circ}$ da Acta Geral da Conferência de Berlim (26 de Fevereiro de 1885) determinava que todas as nações signatárias, além da 'proteção especial aos missionários cristãos', deveriam garantir a liberdade pública de todos os cultos, não podendo assim colocar qualquer entrave à ação evangelizadora, quaisquer que fossem as nacionalidades ou os credos dos missionários. Portugal volta a subscrever este princípio quando ratifica o Convênio Luso Britânico (2 de Julho de 1890) e a Acta Geral da Conferência de Bruxelas (11 de Junho de 1891). Após a I Guerra Mundial, os acordos do Tratado de St. Germain - em - Laye (1919) reafirmam essas disposições, impondo as novas disposições legislativas tomadas pelo governo português (MARQUES, 2001, p. 53). MARQUES, A. H. de Oliveira. Introdução In MARQUES, A. H. de Oliveira. Nova história da expansão portuguesa. Op cit...

${ }^{4}$ Mesmo durante o período republicano (1910 - 1926, a presença das missões protestantes no território Angolano sempre trouxe um desconforto para as autoridades locais. Norton de Matos, em 1921, cria um dispositivo legal para controlar a presença dessas missões, o Decreto $\mathrm{n}^{\circ} 77$, de Dezembro de 1921 estipulava que" [...] compete ao governo da província, como direito de soberania, regulamentar e fiscalizar a ação das missões de propaganda religiosa, de forma a velar pela segurança e ordem pública e a garantir a manutenção dos preceitos do direito constitucional português. (THOMAZ, 2001, p.11). THOMAZ, Omar Ribeiro. O bom povo português: usos e costumes d'aquém e d'além mar, 04/2001, Mana (Rio de janeiro), Vol. 1, pp.55-88, Rio de Janeiro, 2001.

${ }^{5}$ HENDERSON, Lawrence W. A Igreja em Angola: um rio com várias correntes. Lisboa: Além-Mar, 1990, p. 293.

${ }^{6}$ Conforme Oliveira Marques (2001), para o Estado Português, além da "ameaça protestante", ainda havia as influências "nefastas" das religiões tradicionais e do islamismo. MARQUES, A. H. de Oliveira. Nova história da expansão portuguesa. Op cit..., p. 52.

${ }^{7}$ Para uma análise mais profunda sobre a presença do cristianismo em Angola destacamos as obras de Manuel Gabriel (1978), Lawrence Henderson (1990) e Antonio Neves (2008). GABRIEL, Manuel Nunes. 
Angola. Cinco séculos de Cristianismo. Edição Liberal, Braga, 1978, HENDERSON, Lawrence. A Igreja em Angola. Editorial Além-Mar, Lisboa, 1990 e Neves, António M. S. S. "As Igrejas e o nacionalismo em Angola", Revista Lusófona de Ciência das Religiões, 13-14: 511 - 526, 2008.

${ }^{8}$ Segundo Claudio Tomás (2009), “As missões protestantes em Angola privilegiavam as zonas rurais como focos para o seu enraizamento e irradiação. Por detrás deste interesse poderá ter estado a ideia de serem zonas habitadas por povos do interior sem contacto com outras sociedades ou com os europeus. As razões porque se terá processado a aderência massiva dos povos desta região terão sido várias". TOMAS, Cláudio Discursos e práticas alternativas de reconciliação nacional e de construção da nação em Angola: O caso da Igreja Evangélica Congregacional de Angola. Dissertação de mestrado, Lisboa: ISCTE- Instituto Universitário de Lisboa, 2009.

${ }^{9}$ A Igreja Metodista criou um fundo financeiro para que angolanos pudessem estudar no exterior, assim sendo no ano de 1947, a Junta Metodista das Missões concedeu uma bolsa de estudos em Medicina a Agostinho Neto, primeiro angolano beneficiário deste fundo e futuro presidente de Angola, para que o mesmo pudesse estudar na Faculdade de Medicina de Coimbra, Portugal. KAVAYA, Martinho. Educação, cultura e cultura do amém: Diálogos do Ondjango com Freyre em Ganda / Benguela / ANGOLA. Mestrado em Educação. Universidade Federal de Pelotas, 2006

${ }^{10}$ FREUDENTHAL, Aida Faria. Angola. In: MARQUES, A. H. de Oliveira. Nova história da expansão portuguesa. Lisboa: Estampa, 2001. v. XI, p. 427.

${ }^{11}$ Maria da Conceição Neto (1997) distribui as missões protestantes de maneira generalista e não destacando possíveis variações internas nestas regiões, mas é importante para pensarmos a relação entre missões religiosas e grupos étnicos angolanos. CONCEIÇÃO NETO, Maria. Ideologias, Contradições e Mistificações da Colonização de Angola no. Século XX. In: Lusotopie. Éditions Karthala, 1997.

${ }^{12}$ FREUDENTHAL, Aida Faria. Angola. In: MARQUES, A. H. de Oliveira. Nova história da expansão portuguesa. Lisboa: Estampa, 2001. v. XI, p. 428.

${ }^{13}$ De acordo com Martinho Kavaya (2006), os protestantes (sobretudo os metodistas) acreditavam que tanto a Igreja quanto a escola eram instituições de igual importância para a conversão religiosa dos angolanos. Em um documento de 1880, citado por ele, a igreja matriz de Boston, nos Estados Unidos, recomendava aos missionários em Angola para que: "[...] não vos apresseis em ensinar muitas coisas novas aos nativos. Ensinai-lhes primeiro o que é mais importante que eles devem aprender e acolher nos seus corações" (ABCFM apud KAVAYA, 2006, p, 1880, p.30).

${ }^{14}$ Segundo Messiant (1998), "Même quando l'engagement missionnaire protestant en Afrique est le fait de sociétés nées d'um réveil protestant en Occident, c'est bien la même œuvre missionnaire que catholiques et protestants entreprennent, avec les mêmes présupposés quant à lanécessité de sauver es âmes et de les amener à une vie chrétienne qui implique toujours une rupture avec les «superstitions et le «péché »-c'est-à-dire dans tous les cas ici avec des aspects essentiels de systèmes religieux qui sont des systèmes de conduite de vie et avec des coutumes vitales à leur organisation sociale" (MESSIANT, 1998, p. 250). MESSIANT, Christine. 'Protestantismes en situation coloniale. Quelles marges?', Lusotopie245-256.1998

${ }^{15}$ Para Messiant (1998) a formação destas elites protestantes trará um grande impacto para o movimento de independência das colônias portuguesas e para a formação dos Estados Nacionais depois do processo de descolonização. "L'analyse precise du champ religieux global et local (pas seulement chrétien) et de son articulation au champ politique de vrait permettre de mieux comprendre, au-de là durôle du ou des protestantismes dans le mouvement nationaliste, les processos socio-politico-culturels à l'œuvre dans ce mouvement (au-de là de son nationalisme), puis dans les États indépendants où des élites protestantes trouvent sans problème leur place d'élite dans des partis marxistes-léninistes athées, mais aussi la place particulière des religions et mouvements religieux dissidents ou indépendants sous la colonisation et les modalités et l'ampleur de leur résurgence actuelle" (MESSIANT, 1998, p. 256). MESSIANT, Christine. 'Protestantismes en situation coloniale. Quelles marges?', Lusotopie245-256.1998.

${ }^{16}$ Em um texto clássico para a história social angolana do século XX, Luanda (1945-1961): colonisés, société coloniale et engagement nationaliste, fruto de sua tese de doutorado, Messiant (1989) define a existência de uma distinção dentro das elites nativas luandenses: de um lado, os "antigos assimilados", geralmente descendentes de famílias crioulas secularmente instaladas em Luanda, e, por outro, os "novos assimilados", oriundos do interior de Angola e sem laços biológicos com as famílias crioulas. Apesar da relutância em utilizar esses termos, por eles não terem uma conotação jurídica, e, sim, cultural, acreditamos que eles são úteis e operacionais para entendermos a realidade luandense de meados do século XX.

${ }^{17}$ Diferentes aspectos destes personagens e de outros angolanos foram analisados em nossa tese de doutorado (2013) no qual pesquisamos sobre a presença dos "novos assimilados" em Luanda entre os anos de 1926 e 1961. NASCIMENTO, Washington Santos. Gestes do Mato: os "novos assimilados" em Luanda. Tese de 
Doutorado. Faculdade de Filosofia Letras e Ciências Humanas da Universidade de São Paulo, São Paulo, 2013.

${ }^{18}$ BENJAMIN, Walter. O Narrador: considerações sobre a obra de Nikolai Leskov. In: Magia e técnica, arte e política: ensaios sobre literatura e história da cultura. São Paulo: Brasiliense, 1994, p. 197-221.

${ }^{19}$ Uanhenga Xitu ou Agostinho André Mendes de Carvalho, seu nome em português, nasceu no dia 29 de agosto de 1924, na sanzala de Kalomboloca, no Ícolo e Bengo, Angola. Prefere ser chamado por seu pseudônimo literário Uanhenga Xitu, originário da língua quimbundo. Estudou e conseguiu se tornar enfermeiro. Por suas ações nacionalistas foi preso em 1959, pela polícia política do Estado colonial-fascista (PIDE/DGS), acusado de participar em atividades políticas revolucionárias consideradas subversivas e atentatórias à integridade do regime colonial português. Cumpriu parte dessa pena de prisão no período entre 1962 e 1970, no campo de concentração do Tarrafal, em Cabo Verde. Membro do MPLA desde o primeiro momento, ainda hoje é uma de suas principais referências. Escreveu uma série de obras $\mathrm{O}$

Meu Discurso (1974); Mestre Tamoda (1974); Bola com Feitiço (1974); Manana (1974); Vozes na Sanzala (Kahitu) (1976); Mestre Tamoda e outros contos (1977); Maka na Sanzala (1979);

Sobreviventes da Máquina Colonial Depõem (1980); Discursos do Mestre Tamoda (1984); O Ministro (1989); Cultos Especiais (1997)

${ }^{20}$ Adriano Sebastião foi um militante político que participou de diferentes grupos políticos angolanos como o Partido de Luta Unida por Angola (PLUA), fez parte do governo do Movimento pela Libertação de Angola (MPLA) desde o seu primeiro momento, sendo Embaixador de Angola em Portugal. Escreveu o livro de memórias "Dos campos de algodão aos dias de hoje" e "Missombo".

${ }^{21}$ Além da estrutura interna, é possível ver no jornal informações sobre o cotidiano e imagens da missão. Jornal Oficial. West Central Africa Mission Conference, $6^{a}$ edition, 1909.

${ }^{22}$ Este não foi o único movimento de que participou João Fragoso, tampouco sua primeira deportação, pois em 1956 foi para Santo António do Zaire, em 1961, para Mussombo e mais tarde para São Nicolau, CaboVerde. FRAGOSO, José Adão. O Meu Testemunho. Edição do autor. Luanda, 2010.

${ }^{23}$ Em 2010, a igreja de Rangel completou 45 anos de existência, sendo destaque no Jornal local. CALONGO, Carlos. Comunidade do Rangel com mais um ano de vida. Jornal de Angola, 16 de Setembro de 2010. Disponível em http://jornaldeangola.sapo.ao/18/0/ comunidade_do_rangel_com_mais_um_ano_de_vida. Acesso em 10 de Agosto de 2012.

${ }^{24}$ Segundo Arnaldo Santos (2004), Quihamba ou Kihamba era uma corda que ampara pela cintura o trepador de coqueiros e que designava também o próprio trepador. SANTOS, Arnaldo. A Casa velha das margens. Luanda. Edições Maianga, 2004, p. 394.

${ }^{25}$ Kabengele Munanga faz esta discussão em 1986 em sua tese de doutorado sobre os Basanga de Shaba, um grupo étnico existente na atual República Democrática do Congo, antigo Zaire. Munanga volta a esta discussão em 1996 quando trata das sociedades africanas em meio a uma discussão sobre os quilombos na África. MUNANGA, Kabengele. Os Basanga de Shaba, Um Grupo Etnico do Zaire. São Paulo: FFLCH/USP, 1986. 334 p. e MUNANGA, Kabengele. Origem e Histórico do Quilombo na África. Revista USP v. 28, p. 56-64, 1995/1996.

${ }^{26}$ JORGE, Manuel. Nação, identidade e unidade nacional em Angola. In Latitudes: Cahiers Lusophones, France, 2006, p. 3-10 e JORGE, Manuel. Para Compreender Angola, Lisboa: Dom Quixote, 2008, 296p.

${ }^{27}$ Para Manuel Jorge (1998): “A angolanidade constrói-se com tudo aquilo que a História legou ao povo angolano: o substrato negro africano e os elementos da cultura dominante que, ao longo dos séculos, penetraram até ao fundo do inconsciente popular. Será que essa concepção conduz à aceitação da condição de mestiço cultural? Absolutamente, não! É que essa concepção é a única que seja conforme a realidade. Ela parte do princípio que não há cultura pura, como não há raça pura. E é por isso que devemos assumir, plena e inteiramente, a realidade histórica que forjou Angola e a sua cultura (JORGE, 1998, p.8)”. JORGE, Manuel. Para Compreender Angola. Op cit...

${ }^{28}$ Para Alessandro Portelli (1997), uma entrevista é um processo de troca e interferência mútua, em que tanto entrevistador quanto entrevistado influenciam um ao outro. Segundo ele "[...] uma entrevista é uma troca entre dois sujeitos: literalmente uma visão mútua. Uma parte não pode realmente ver a outra a menos que a outra possa vê-lo ou vê-la em troca" (PORTELI, 1997, p.11). PORTELLI, Alessandro. Forma e significado na História Oral: a pesquisa como um experimento em igualdade. Projeto História, v. 14, p. 7-24, fev. 1997

${ }^{29}$ Escritor angolano, Raúl Mateus David nasceu a 23 de abril de 1918, na província de Benguela, na cidade da Ganda, Angola. Terminou o ensino secundário no Seminário Menor do Sagrado Coração de Jesus, no Galangue. Trabalhou em diferentes atividades, de funcionário público de profissão a feitor em fazendas do interior do país. Suas obras se destacam pelo estudo do passado colonial nas zonas interioranas de Angola, como em Colonizados e colonizadores (1974); Escamoteados na Lei (1977); Contos Tradicionais da Nossa 
Terra (I) (1978); Narrativas ao acaso (1979); Contos Tradicionais da Nossa Terra (II) (1981), Cantares do Nosso Povo (1988); Crónicas de Ontem para Ouvir e Contar (1989); Da Justiça Tradicional dos Umbundos (1997). Foi um dos membros fundadores da União dos Escritores Angolanos (UEA), referência pessoal e literária, "mais velho", era chamado pelas pessoas mais próximas de "Ti Raul", apesar de sua importância e reconhecimento público, nunca quis, nem exerceu cargos públicos. Faleceu em 20 de fevereiro de $2005 \mathrm{em}$ Lobito, província de Benguela. Quando de sua morte o escritor Boaventura Cardoso, então ministro angolano da Cultura, disse que "É uma biblioteca que desaparece, perdemos uma enciclopédia viva do passado colonial". CARDOSO, Boaventura. Prefácio a 1 a Edição In DAVID, Raul. Escamoteados na Lei. União, Endiama, Porto do Lobito. 1990 Morreu escritor angolano Raul David, autor de "Colonizados e Colonizadores" Agência LUSA.21 Fev, 2005, 11:28. Disponivel em http://www.rtp.pt/noticias/index.php?article $=153039 \& \mathrm{tm}=4 \&$ layout=121\&visual=49.

30 A sua entrevista foi uma das mais ricas para o problema de pesquisa por nós proposto e será analisada também em outros momentos desta tese.

${ }^{31}$ Segundo Maria Martins (2008), "No enclave de Cabinda, a missão era Lândana, e era masculina e feminina com internato. A circunscrição missionária do interior de Benguela era a mais próspera e progressiva dos padres do Espírito Santo. As missões principais eram as de Caconda, Bailundo e Huambo. Tinham padres e leigos preparados em três casas na Metrópole; uma de missionários presbíteros, outra de auxiliares leigos em Braga e outra ainda para estudos complementares em Viana do Castelo. As missões do planalto da Huíla eram as mais florescentes, a seguir, as do planalto de Benguela. Geograficamente, eram excelentes, de clima temperado e de boas possibilidades agrícolas. Eram, como as de Cabinda, missões modernas e modernamente organizadas, onde a economia e o trabalho europeus foram integrados na vida do indígena" (MARTINS, 2008, p. 303). MARTINS, Maria Odete Soares - O pensamento missionário do padre Joaquim Alves Correia (1886-1951). Lusitania Sacra. Lisboa, 2007-2008.

${ }^{32}$ Iracema Dulley (2010) constrói este quadro com base nas fontes coletadas no centro de documentação da Congregação do Espírito Santo. DULLEY, Iracema. Deus é feiticeiro - prática e disputa nas missões católicas em Angola colonial. São Paulo: Annablume. 2010, p.34.

${ }^{33}$ Nasceu em 1946 na localidade de Mumondo, município da Muxima, província do Bengo, fez os estudos primários e secundários no antigo colégio São José de Cluny. Sob o pseudônimo de Dya Kasembe publicou, "Angola 20 anos de guerra civil, uma mulher acusa" (1995), "As mulheres honradas e insubmissas de Angola" Nzila, 2005, "Amores da Sanzala" e "Cartas para maridos temerários" (2002).

34 HAROCHE, Claudine. "Les exigences de la reconnaissance dans les sociétés démocratiques". In: E. Enriquez (ed.), Le Goût de l'altérité, Paris, Desclée de Brouwer, 1999. LETRAS GRUDADAS

${ }^{35} \mathrm{O}$ nome completo de Nito Alves era Alves Bernardo Baptista, mais conhecido como Nito Alves, foi guerrilheiro da $1^{a}$ região Político-militar durante a guerra de libertação, aparece com mais evidência no Movimento durante o Congresso de Lusaka, em 1974, defendendo as posições do presidente Agostinho Neto. Segundo Inácio Marques (2011) "Como aliado chegou aos altos escalões do Movimento, o que lhe rendeu o cargo de Ministro da Administração Interna no primeiro governo independente, em 1975. Durante o ano de 1976, grosso modo, sua posição político-ideológica - a favor do estabelecimento de um governo marxista leninista - foi progressivamente conquistando adeptos e, ao mesmo tempo, provocando atritos com o Governo, que ao contrário insistia em uma chamada revolução democrática e popular que não ameaçasse sua legitimidade. Em outubro deste mesmo ano foi acusado, juntamente com seus principais aliados, José-VanDunem e Sita Vales, de traição, o que lhe custou a perda do cargo de ministro. Apesar disso, não cedeu aos pedidos para que se calasse, o que rendeu a Nito Alves - e também a Van-Dunem - a expulsão formal em 20 de maio de 1977 dos quadros do Movimento. Apenas uma semana depois, no dia 27, tentaria sem sucesso derrubar o governo" (MARQUES, 2011, p. 1). MARQUES, Inácio Luiz. As memórias do 27 de maio de 1977 em Angola. Anais do XXVI Simpósio Nacional de História - ANPUH • São Paulo, julho 2011.

Recebido em abril-2014

Aprovado em maio-2014 